\title{
WIP: Validating a Motivated Strategies for Learning Questionnaire (MSLQ) in an Active, Blended, and Collaborative (ABC) Dynamics Learning Environment
}

\author{
Ms. Wonki Lee, Purdue University-Main Campus, West Lafayette (College of Engineering)
}

Wonki Lee is pursuing Ph.D. in Education, Curriculum Instruction, Language and Literacy program at Purdue University. She received her bachelors and masters, specializing Korean language education as second/foreign language from Seoul National University, South Korea. Prior her doctoral studies in United States, she worked as a Korean teacher for 6 years and pursued her Ph.D. in South Korea. She currently works as graduate research assistant in engineering education department. Her research interests are assessment for learners in diverse settings, and teacher education in multicultural settings.

\section{Prof. Jeffrey F Rhoads, Purdue University at West Lafayette}

Jeffrey F. Rhoads is a Professor in the School of Mechanical Engineering at Purdue University and is affiliated with both the Birck Nanotechnology Center and Ray W. Herrick Laboratories at the same institution. He received his B.S., M.S., and Ph.D. degrees, each in mechanical engineering, from Michigan State University in 2002, 2004, and 2007, respectively. Dr. Rhoads' current research interests include the predictive design, analysis, and implementation of resonant micro/nanoelectromechanical systems (MEMS/NEMS) for use in chemical and biological sensing, electromechanical signal processing, and computing; the dynamics of parametrically-excited systems and coupled oscillators; the thermomechanics of energetic materials; additive manufacturing; and mechanics education. Dr. Rhoads is a Member of the American Society for Engineering Education (ASEE) and a Fellow of the American Society of Mechanical Engineers (ASME), where he serves on the Design Engineering Division's Technical Committees on Micro/Nanosystems and Vibration and Sound, as well as the Design, Materials, and Manufacturing (DMM) Segment Leadership Team. Dr. Rhoads is a recipient of numerous research and teaching awards, including the National Science Foundation's Faculty Early Career Development (CAREER) Award; the Purdue University School of Mechanical Engineering's Harry L. Solberg Best Teacher Award (twice), Robert W. Fox Outstanding Instructor Award, and B.F.S. Schaefer Outstanding Young Faculty Scholar Award; the ASEE Mechanics Division's Ferdinand P. Beer and E. Russell Johnston, Jr. Outstanding New Mechanics Educator Award; and the ASME C. D. Mote Jr., Early Career Award. In 2014 Dr. Rhoads was included in ASEE Prism Magazine's 20 Under 40.

\section{Dr. Edward J. Berger, Purdue University at West Lafayette}

Edward Berger is an Associate Professor of Engineering Education and Mechanical Engineering at Purdue University, joining Purdue in August 2014. He has been teaching mechanics for over 20 years, and has worked extensively on the integration and assessment of specific technology interventions in mechanics classes. He was one of the co-leaders in 2013-2014 of the ASEE Virtual Community of Practice (VCP) for mechanics educators across the country. His current research focuses on student problem-solving processes and use of worked examples, change models and evidence-based teaching practices in engineering curricula, and the role of non-cognitive and affective factors in student academic outcomes and overall success.

\section{Prof. Jennifer DeBoer, Purdue University at West Lafayette}

Jennifer DeBoer is currently Assistant Professor of Engineering Education at Purdue University. Her research focuses on international education systems, individual and social development, technology use and STEM learning, and educational environments for diverse learners. 


\section{WIP: Validating a Motivated Strategies for Learning Questionnaire (MSLQ) in an Active, Blended, and Collaborative (ABC) Dynamics Learning Environment}

\section{Introduction}

In engineering education research, students' motivation and learning strategies are often measured using the Motivated Strategies for Learning Questionnaire (MLSQ). The sociocognitive foundation on which this survey was established assumes that motivation and learning strategies are not inherent attributes of the learner, but rather are contextually attached. Although the MSLQ scales have been extensively tested in different subject-matter contexts in engineering, this study aims to examine the MSLQ constructs and factor structures in a novel engineering educational setting.

This paper validated three MSLQ subscales in an “ABC” learning environment for engineering dynamics: (A) Active learning, (B) blended structures, (C) and collaborative student engagement that have shown to be highly influential for university-level engineering students. This unique class environment exhibits several features that make it a new and distinct educational setting in which to validate the MSLQ.

Preliminary results suggest the existence of two separate self-efficacy factors in this ABC context: one related to performance and one related to conceptual understanding. Engineering education researchers and instructors would benefit from further understanding what affects the divergence of self-efficacy factors.

\section{Background}

Measuring Self-Regulate Learning

The learner intentionally organizes his or her learning process using metacognitive, motivational, and behavioral strategies. Self-regulated learning is an active process within and between these strategies, and the degree of learners' using these strategies where successful students employ multiple factors of self-regulative components in their learning [1], [2]. The MSLQ is one of the most extensively used scales designed to assess self-regulated learning [3]. Pintrich and colleagues developed the MSLQ [2] to measure three components (motivation, metacognition, and behavior) of self-regulated learning [2]. It has been widely validated and deployed in university engineering education settings.

The MSLQ has two parts: Motivation and Learning Strategies. Motivation scales are composed of three dimensions (value, expectancy, and affective) with 31 items subdivided into six subscales: intrinsic goal orientation, extrinsic goal motivation, task value, control beliefs, self-efficacy for learning and performance, and test anxiety. The learning strategies scale measures two dimensions (cognitive and metacognitive strategies, resource management 
strategies) with 50 items subdivided into nine subscales: rehearsal, elaboration, organization, critical thinking, metacognitive self-regulation, time and study environment, effort regulation, peer learning, and help seeking.

\section{Motivation in Engineering Education Contexts}

The MSLQ measures student motivation, self-regulation, and learning strategies [4]. This scale adapted the social cognitive view of motivation and self-regulated learning [2], which assumes motivation and learning strategies are not static characteristics innate to the learner, but are rather dynamic, contextually-embedded constructs under the control of the student [5]. In this context, the learner actively, cognitively processes the input, while engaging and negotiating the learning environment and react differently depend on the context. In other words, motivation and learning strategies can be differently established based on the study subject, and teaching methods. For instance, engineering students struggled with goals and beliefs when they take required foundational courses outside of their major [6].

The motivation of a learner can shift from course to course based on the efficacy of interest, and learning strategies may vary depending on the designs and features of a learning task [7], [8]. In engineering education, with meaningful advances of the traditional engineering education course environment, various forms of alternative classrooms have more recently served as new contexts in which to study student motivation. For instance, motivations in online learning and blended learning [9]-[11]; active, collaborative learning in a small group [12]; and flipped learning [13] classrooms suggested the existing factor structure can be differentiated depend on the engineering learning context.

\section{The MSLQ in Various Engineering Education Contexts}

The MSLQ in engineering education was utilized as a popular tool to see the changes of motivational/strategic status [13]-[15] and to see the relationship between motivational constructs and GPA [16]-[20]. Although validation studies of the MSLQ proposed various factor structures or models depending on the study population and environment [21]-[23], engineering education has been focused on different cultural or national settings [1], [24], or social cognitive constructs validation based on gender differences [25].

Additionally, subscales have been adopted as a module to develop a new scale specific to a certain engineering context [15], [26], [27]. However, these studies applied and utilized the MSLQ in engineering education without validating the scale. Considering that the design of the MSLQ items and factor structures are for the traditional classroom (teacher-centered, face-toface lecture, quiz, homework without supplemental online materials) and general college population rather than focusing on specific major, this might overlook the unique dynamics of the blended, collaborative classroom and not reflect the self-regulative learning experiences of learners. 


\section{The MSLQ in the Freeform context}

In 2008, an active, blended, and collaborative (ABC) teaching and learning environment for a core engineering science course (Dynamics), named Freeform, was developed and adopted by a team of mechanics instructors [28]. With the goal of a student-centered classroom, Freeform transformed a lecture-based pedagogical environment to a highly-networked pedagogical environment. The hybrid nature of course resources (i.e., instructor-produced videos, hybrid textbooks which combined a traditional textbook and significant white space for note taking, and a course blog) allowed the students to actively, collaboratively engage in the class and manage multiple, aligned study resources asynchronously.

Based on the above-mentioned innovative nature of the Freeform learning context, this study adapted the instrument of three MSLQ sub-scales to examine the motivational construct and learning strategies in a Freeform setting. Within the MSLQ (Appendix 1), we selected three subscales: self-efficacy for learning and performance $(n=8)$, test anxiety $(n=5)$, and time study environment $(n=8)$, replacing the words "class" in the scale items with "ME274", the name of the course.

\section{Self-Efficacy for Learning and Performance}

The MSLQ measures two aspects of expectancy: expectancy for performance and selfefficacy (one's self-appraisal of the ability to master a task). These two aspects belong to the same factor and showed high coefficient alpha (.93) with the final grades in the original MSLQ description [2].

\section{Test anxiety}

The MSLQ includesd test anxiety as a factor of affective component. This component includes both an emotionality and cognitive component. Emotionality refers to affective and physiological aspects, like worries. The cCognitive component of test anxiety includes cognitive concern and preoccupation with performance. Test anxiety was negatively correlated to academic performance $(\alpha=.80)$ [2].

\section{Time and study environment}

Self-regulation of time and study environment (TSE) is important for one's successful learning, and this factor also was highly correlated with the final grade $(\alpha=.76)$. It encompasses scheduling, planning, and study time management, with setting aside time to study and effective utilizing utilization of the study time. Study environment characterizes the setting for studying the coursework. Major claims in here is, structured, organized and quiet study space without distraction is considered optimal study environment [2], [29]. 
The Freeform environment alters the time and study environment factors of students. Student can utilize the learning materials with support of colleagues, asynchronously. This learning context offers student support synchronously and asynchronously by employing blogs, lecture videos and tutorial rooms with teaching assistants. With multiple online/offline sources, this environment fosters students' participation and engagement while improving students' preparedness [30]. Developing better study strategies reduces text anxiety of the learners [2], changing the perceptions of self in this course.

\section{Research Question}

Considering the original factor structure of the MSLQ [4] was not appropriate in a more active, student-centered learning context [19]-[22] compared to the traditional classroom that is more widely used in core engineering sciences contexts, this study aims to validate three subscales of the MSLQ in our ABC engineering educational setting, a contradistinctive context compared to a less-active general classroom with fewer or no digital resources. The specific research questions are:

1) What is the internal validity of the MSLQ in the Freeform setting?

2) What is the predictive validity of the MSLQ in the Freeform setting?

\section{Research Design and Methods}

Participants and Data Collection

A total of 681 students enrolled in Freeform dynamics classes at a large midwestern university in the United States participated in this study during the 2017 (Spring, Summer, and Fall) - 2018 (Spring, Summer, and Fall). These research procedures were approved by the university's Institutional Research Board, and all participants supplied informed consent for this research study.

\section{Measures}

The MSLQ [2] contains 81 items scored on a 7-point Likert scale ( 1 = "Not at all true of me" to 7 = "Very true of me") and unevenly distributed over 15 subscales comprising two sections: Motivation and Learning Strategies. In this study, three subscales of the MSLQ were implemented: self-efficacy and test anxiety from the Motivation section and time study environment from the Learning Strategies section (see Appendix 1).

\section{Data Analysis and Results}

Stage 1. The internal validity of the scale with three latent factors (self-efficacy for learning and performances, test anxiety, and time study environment) employed by MSLQ (see Appendix 1) and align with the MSLQ structure were validated using confirmatory factor analysis (CFA). Model fit indices of the proposed MSLQ subscales were below the threshold levels, and not acceptable (RMSEA $=0.111$, CFI $=0.811$, TLI $=0.787$, GFI $=0.789, \chi^{2}=$ 1739.859, $\mathrm{df}=186$ ), it is recommended to have a threshold levels (RMSEA <.07, CFI, TLI, GFI 
greater than .95 is good and greater than .90 is acceptable, and for $\chi^{2}$, the smaller, the better) [31], [32].

Stage 2. The original items were subjected to an exploratory factor analysis (EFA) for uncovering stable underlying factors and factor structure. The maximum likelihood factor analysis was used with Promax rotation, an oblique rotation that allows factors to be correlated and is useful for large datasets. The Kaiser-Meyer-Olkin measure of sampling adequacy index was .889, as a measure of homogeneity of variables. Bartlett's test of sphericity was significant $\left(\chi^{2}(190)=8171.032, \mathrm{p}<.001\right)$.

A total of two items in time study environment which did not share common variance failed to meet a minimum criteria . 3 with other items were eliminated: TSE 6 ("I attend class regularly”) and TSE 8 ("I rarely find time to review my notes or readings before exams.”).

Though the original MSLQ consisted of 3 factors, the scree plot recommended a 3- or 4factor solution. The three-factor solution explained a total of $56.85 \%$ of the variance, and the four-factor solution explained a total of $58.60 \%$ of the variance. For the three-factor structure, five items cross-loaded on self-efficacy for learning and performance and test anxiety, and two items were not explained by any of the suggested factors. The four-factor structure displayed a clearer factor structure without any cross-loadings. A four-factor structure, which yielded more robust results [33], was selected (see Appendix 2, 3).

According to the factor score means, Factor 1 (self-efficacy including performance expectations) showed the highest factor score (6.269), and Factor 4 (time study environment) had the lowest score (1.391). All factor loadings above .40 were retained.

In the four-factor solution, test anxiety and time study environment test items were loaded on the same factor. However, self-efficacy for learning and performance test items loaded on two separate factors. The first factor of the self-efficacy for learning and performance includes performance expectations [2] (SE1, SE2, SE4, and SE5), and the second factor of the self-efficacy subsumes items ascribing comprehension (SE3, SE6, SE7, and SE8).

Stage 3. The four-factor model of the MSLQ from Stage 2 was validated using CFAstructural equation modeling (SEM). This model fit showed improved indices (RMSEA = 0.069, $\mathrm{CFI}=0.927, \mathrm{TLI}=0.917$, GFI $=0.898, \chi^{2}=779.871, d f=183$ ) compared to the model from Stage 1.

Stage 4. Several modifications were introduced by the Lagrange Multiplier test for the statistical significance of the omitted paths [34]. Within this, four modifications were adopted, given that these modifications were theoretically acceptable which means correlations within the factor and greatly improved the model fit indices. All modifications were the correlation between 
the test items within the factor. Pathways were added between TSE1 and TSE2; TSE1 and TSE4; TA2 and TA3; and SE6 and SE7. These pathways significantly improved the model fit (RMSEA $=0.054, \mathrm{CFI}=0.956, \mathrm{TLI}=0.949, \mathrm{GFI}=0.926, \chi^{2}=539.966, d f=179$ ).

Stage 5. The predictive validity of the model from Stage 3 was examined using CFASEM (see Appendix 5). Out of the four suggested factors, time study environment, test anxiety, and the second factor of self-efficacy did not have significant predictive power for academic performance as measured by course grade. The first factor of self-efficacy (SE1, SE2, SE4, and SE5) was the only significant predictor of academic outcomes (See Appendix 4).

\section{Discussion, Conclusions, and Next Steps towards Work in Progress}

The results suggest an alternative factor structure with two self-efficacy factors in the Freeform setting. The MSLQ included self-efficacy for learning and performance in the same subscale, asserting that they comprise the same factor. The items in this scale assess two dimensions of expectancy: expectancy for success and self-efficacy to accomplish the task [2].

The first factor describes items with expectancy for success, which refers to performance expectations [2]. This factor embodies items with students' perceptions and their beliefs of academic achievement. The second factor, including the items related to the self-efficacy to accomplish the task [2], represents students' self-appraisal of their ability to understand the course materials. These results imply that engineering students have distinct perceptions of selfefficacy between their understanding of course materials and performance. It also supports other research findings in the engineering context that self-efficacy with academic milestones differs from other coping self-efficacy (i.e., adjusting to a new environment, be a part of the group of engineering students), and predicts academic performance [35].

Also, out of the two self-efficacy factors, only performance-self-efficacy predicted academic performance, which means self-perception of conceptual understanding aligns with previous studies that suggested conceptual understanding alone is not sufficient to predict students' grades [36]. Instead, problem-solving skills with qualitative understanding and verbal explanation can predict students' achievement [37]. This implies students are cognizant that the current status of conceptual understanding is somewhat different from getting a good grade.

Test anxiety did not significantly predict students' grades in the Freeform environment, which aligns with the previous study [38] that investigated engineering education students' test anxiety and suggested that test anxiety may not be a direct predictor of the final grade but a negative predictor of self-efficacy. Studies suggested that cognitive test anxiety, which related to individuals' cognitive attitudes to the assessment, would lead to a more accurate prediction of students' academic achievement [39]. Furthermore, for the engineering student, 
multidimensional perspectives and mental workloads and demands should be considered for successful problem-solving that leads to successful learning [40].

The time study environment also failed to predict academic achievement. The asynchronous nature of the blended learning environment may switch the time study environment of the student. Also, students in the Freeform setting showed high attendance [41], and lower DFW rates [30] compared to other "typical” engineering sciences course contexts. This may contribute to what we observe as a different time study environment factor structure.

This study provides implications for psychometrically valid measures for gauging and characterizing engineering students' motivation. This helps to understand the unique motivational aspects of self-efficacy, test anxiety, and time study environment in the Freeform setting. The next steps for this work will bridge the gap between conceptual understanding and actual performance, developing ways to help students expand conceptual knowledge. 


\section{References}

[1] J. J. Ramírez Echeverry, À. García Carrillo, and F. A. Olarte Dussan, “Adaptation and validation of the motivated strategies for learning questionnaire-MSLQ-in engineering students in Colombia,” Int. J. Eng. Educ., vol. 32, no. 4, pp. 1774-1787, 2016.

[2] P. R. Pintrich, "A manual for the use of the Motivated Strategies for Learning Questionnaire (MSLQ).,” 1991.

[3] B. J. Zimmerman, “A social cognitive view of self-regulated academic learning.,” J. Educ. Psychol., vol. 81, no. 3, pp. 329-339, 1989.

[4] P. R. Pintrich and E. V. De Groot, "Motivational and self-regulated learning components of classroom academic performance.,” J. Educ. Psychol., vol. 82, no. 1, p. 33-40, 1990.

[5] T. G. Duncan and W. J. McKeachie, "The making of the motivated strategies for learning questionnaire,” Educ. Psychol., vol. 40, no. 2, pp. 117-128, 2005.

[6] K. G. Nelson, D. F. Shell, J. Husman, E. J. Fishman, and L.-K. Soh, "Motivational and Self-Regulated Learning Profiles of Students Taking a Foundational Engineering Course,” J. Eng. Educ., vol. 104, no. 1, pp. 74-100, 2015.

[7] M. Bong, “Academic motivation in self-efficacy, task value, achievement goal orientations, and attributional beliefs,” J. Educ. Res., vol. 97, no. 6, pp. 287-298, 2004.

[8] D. H. Schunk, "Self-efficacy and academic motivation,” Educ. Psychol., vol. 26, no. 3-4, pp. 207-231, 1991.

[9] L. Barnard, W. Y. Lan, Y. M. To, V. O. Paton, and S.-L. Lai, "Measuring self-regulation in online and blended learning environments,” Internet High. Educ., vol. 12, no. 1, pp. 1-6, 2009.

[10] R. S. Jansen, A. Van Leeuwen, J. Janssen, L. Kester, and M. Kalz, "Validation of the selfregulated online learning questionnaire,” J. Comput. High. Educ., vol. 29, no. 1, pp. 6-27, 2017.

[11] R. Lynch and M. Dembo, "The relationship between self-regulation and online learning in a blended learning context,” Int. Rev. Res. Open Distrib. Learn., vol. 5, no. 2, 2004.

[12] L. Springer, M. E. Stanne, and S. S. Donovan, "Effects of small-group learning on undergraduates in science, mathematics, engineering, and technology: A meta-analysis,” Rev. Educ. Res., vol. 69, no. 1, pp. 21-51, 1999.

[13] E. A. Van Vliet, J. C. Winnips, and N. Brouwer, "Flipped-class pedagogy enhances student metacognition and collaborative-learning strategies in higher education but effect does not persist," CBE-Life Sci. Educ., vol. 14, no. 3, pp. 1-10, 2015.

[14] R. M. Marra and T. Wheeler, "The impact of an authentic, student-centered engineering project on student motivation,” in 30th Annual Frontiers in Education Conference. Building on A Century of Progress in Engineering Education. Conference Proceedings (IEEE Cat. No. 00CH37135), 2000, vol. 2, pp. F2C-8.

[15] R. McCord and H. M. Matusovich, "Developing an Instrument to Measure Motivation, Learning Strategies and Conceptual Change," in ASEE Conference \& Exposition, Atlanta, GA, 2013.

[16] C. M. Vogt, "Faculty as a critical juncture in student retention and performance in engineering programs,” J. Eng. Educ., vol. 97, no. 1, pp. 27-36, 2008.

[17] J. Hampikian, “AC 2007-1998: Benefits of a tutorial mathematics program for engineering students enrolled in precalculus: a template for assessment," in Proceedings of the 2007 American Society for Engineering Education Annual Conference \& Exposition, Honolulu, HI, 2007, pp. 24-27. 
[18] N. S. Samsuri, K. Mohd-Yusof, and A. A. Aziz, "Enhancing the First Year Engineering Student Motivation through an Introductory Engineering Course,” in 2017 7th World Engineering Education Forum (WEEF), Nov. 2017, pp. 349-354.

[19] N. Honken, P. A. Ralston, and T. R. Tretter, "Self-Control and Academic Performance in Engineering.," Am. J. Eng. Educ., vol. 7, no. 2, pp. 47-58, 2016.

[20] W.-T. Chung, G. Stump, J. Hilpert, J. Husman, W. Kim, and J. E. Lee, “Addressing engineering educators' concerns: Collaborative learning and achievement,” in 2008 38th Annual Frontiers in Education Conference, 2008, pp. T3A-3.

[21] L. Hu and P. M. Bentler, "Cutoff criteria for fit indexes in covariance structure analysis: Conventional criteria versus new alternatives,” Struct. Equ. Model. Multidiscip. J., vol. 6, no. 1, pp. 1-55, 1999.

[22] M.-H. CHo and J. Summers, "Factor validity of the Motivated Strategies for Learning Questionnaire (MSLQ) in asynchronous online learning environments,” J. Interact. Learn. Res., vol. 23, no. 1, pp. 5-28, 2012.

[23] C. Magno, "Validating the academic self-regulated learning scale with the motivated strategies for learning questionnaire (MSLQ) and learning and study strategies inventory (LASSI),” Int. J. Educ. Psychol. Assess., vol. 7, no. 2, pp. 56-73, 2011.

[24] C. R. Jackson, "Validating and adapting the Motivated Strategies for Learning Questionnaire (MSLQ) for STEM courses at an HBCU,” Aera Open, vol. 4, no. 4, pp. 1-16, 2018.

[25] C. M. Vogt, D. Hocevar, and L. S. Hagedorn, “A social cognitive construct validation: Determining women's and men’s success in engineering programs,” J. High. Educ., vol. 78, no. 3, pp. 337-364, 2007.

[26] J. C. Hilpert, G. Stump, and J. Husman, "Pittsburgh engineering attitudes scale-Revised: Evidence for an improved instrument," in 2010 IEEE Frontiers in Education Conference (FIE), 2010, pp. T2G-1.

[27] D. Parsons, "Is there an alternative to exams? Examination stress in engineering courses," Int. J. Eng. Educ., vol. 24, no. 6, pp. 1111-1118, 2008.

[28] J. F. Rhoads, E. Nauman, B. M. Holloway, and C. M. Krousgrill, “The Purdue Mechanics Freeform Classroom: A new approach to engineering mechanics education,” in 121st ASEE Annual Conference \& Exposition, Indianapolis, IN. June 15-18, 2014, 2014.

[29] P. R. Pintrich, D. A. Smith, T. Garcia, and W. J. McKeachie, "Reliability and predictive validity of the Motivated Strategies for Learning Questionnaire (MSLQ),” Educ. Psychol. Meas., vol. 53, no. 3, pp. 801-813, 1993.

[30] J. DeBoer et al., "Work in progress: Rigorously assessing the anecdotal evidence of increased student persistence in an active, blended, and collaborative mechanical engineering environment,” in ASEE Conference \& Exposition, New Orleans, LA, 2016.

[31] D. Gefen, E. E. Rigdon, and D. Straub, “Editor's comments: an update and extension to SEM guidelines for administrative and social science research,” Mis Q., pp. iii-xiv, 2011.

[32] L. A. Bryan, "Nestedness of beliefs: Examining a prospective elementary teacher's belief system about science teaching and learning,” J. Res. Sci. Teach., vol. 40, no. 9, pp. 835868, 2003.

[33] B. Williams, A. Onsman, and T. Brown, "Exploratory factor analysis: A five-step guide for novices,” Australas. J. Paramed., vol. 8, no. 3, pp. 1-13, 2010.

[34] D. Sörbom, “Model modification,” Psychometrika, vol. 54, no. 3, pp. 371-384, 1989. 
[35] J. P. Concannon and L. H. Barrow, "A cross-sectional study of engineering students' selfefficacy by gender, ethnicity, year, and transfer status,” J. Sci. Educ. Technol., vol. 18, no. 2, pp. 163-172, 2009.

[36] N. Stites et al., "Analyzing an abbreviated dynamics concept inventory and its role as an instrument for assessing emergent learning pedagogies," in 2016 ASEE Annual Conference \& Exposition, 2016.

[37] S. Ates and E. Cataloglu, "The effects of students' cognitive styles on conceptual understandings and problem-solving skills in introductory mechanics," Res. Sci. Technol. Educ., vol. 25, no. 2, pp. 167-178, Jul. 2007.

[38] P.-H. Hsieh, J. R. Sullivan, D. A. Sass, and N. S. Guerra, "Undergraduate engineering students' beliefs, coping strategies, and academic performance: An evaluation of theoretical models,” J. Exp. Educ., vol. 80, no. 2, pp. 196-218, 2012.

[39] J. C. Cassady and R. E. Johnson, "Cognitive Test Anxiety and Academic Performance," Contemp. Educ. Psychol., vol. 27, pp. 270-295, 2002.

[40] S. J. Grigg, S. K. Garrett, and L. C. Benson, "Using the NASA-TLX to assess first year engineering problem difficulty,” in IIE Annual Conference. Proceedings, 2012, p. 1.

[41] P. Purcell, "Engineering student attendance at lectures: Effect on examination performance," in International Conference on Engineering Education, Coimbra, Portugal, 2007. 
Appendix 1. MSLQ: Test item from Selected Subscales

\begin{tabular}{|c|c|c|c|c|}
\hline Section & Scale & Subscale & Item \# & Test Item \\
\hline \multirow[t]{13}{*}{ Motivation } & \multirow[t]{8}{*}{ Expectancy } & \multirow[t]{8}{*}{$\begin{array}{c}\text { Self-Efficacy } \\
\text { (SE) }\end{array}$} & SE1 & $\begin{array}{l}\text { I am confident I can do an excellent job on the assignments and tests in ME } \\
274 .\end{array}$ \\
\hline & & & SE2 & I expect to do well in ME 274. \\
\hline & & & SE3 & I am certain I can master the skills being taught in ME 274. \\
\hline & & & SE4 & $\begin{array}{l}\text { Considering all the aspects of the course - the difficulty of this course, the } \\
\text { teacher, and my skills - I think I will do well in ME } 274 \text {. }\end{array}$ \\
\hline & & & SE5 & I believe I will receive an excellent grade in ME 274. \\
\hline & & & SE6 & $\begin{array}{l}\text { I am certain I can understand the most difficult material presented in ME } \\
274 .\end{array}$ \\
\hline & & & SE7 & $\begin{array}{l}\text { I am confident I can understand the most complex material presented by the } \\
\text { instructor in ME } 274 \text {. }\end{array}$ \\
\hline & & & SE8 & I am confident I can understand the basic concepts taught in ME 274. \\
\hline & \multirow[t]{5}{*}{ Affect } & \multirow[t]{5}{*}{$\begin{array}{c}\text { Test-Anxiety } \\
\text { (TA) }\end{array}$} & TA1 & $\begin{array}{l}\text { When I take a test, I think about how poorly I am doing compared with other } \\
\text { students. }\end{array}$ \\
\hline & & & TA2 & I have an uneasy, upset feeling when I take an exam. \\
\hline & & & TA3 & I feel my heart beating fast when I take an exam. \\
\hline & & & TA4 & When I take tests, I think of the consequences of failing. \\
\hline & & & TA5 & $\begin{array}{l}\text { When I take a test, I think about items on other parts of the test I can't } \\
\text { answer. }\end{array}$ \\
\hline \multirow{8}{*}{$\begin{array}{l}\text { Learning } \\
\text { Strategies }\end{array}$} & \multirow{8}{*}{$\begin{array}{c}\text { Resource } \\
\text { Management }\end{array}$} & \multirow{8}{*}{$\begin{array}{l}\text { Time Study } \\
\text { Management } \\
\text { (TSE) }\end{array}$} & TSE1 & I usually study in a place where I can concentrate on my course work. \\
\hline & & & TSE2 & I make good use of my study time for my courses. \\
\hline & & & TSE3 & I find it hard to stick to a study schedule. \\
\hline & & & TSE4 & I have a regular place set aside for studying. \\
\hline & & & TSE5 & $\begin{array}{l}\text { I make sure I keep up with the weekly readings and assignments for my } \\
\text { courses. }\end{array}$ \\
\hline & & & TSE6 & I attend class regularly. \\
\hline & & & TSE7 & $\begin{array}{l}\text { I often find that I don't spend very much time on my courses because of } \\
\text { other activities. }\end{array}$ \\
\hline & & & TSE8 & I rarely find time to review my notes or readings before exams. \\
\hline
\end{tabular}


Appendix 2. Factor loadings based on an exploratory factor analysis

\begin{tabular}{lllll}
\hline & Factor1 & Factor2 & Factor3 & Factor4 \\
\hline SE2 & .969 & & & \\
SE5 & .934 & & & \\
SE4 & .847 & & & \\
SE1 & .770 & .979 & & \\
SE7 & & .958 & & \\
SE6 & & .592 & & \\
SE3 & .576 & .771 & \\
SE8 & & & .749 & \\
TA2 & & .731 & \\
TA3 & & .624 & .601 \\
TA4 & & & & \\
TA1 & & & & \\
TA5 & & & & .658 \\
TSE2 & & & .589 \\
TSE3 & & & \\
TSE4 & & & & \\
TSE1 & & & & \\
TSE7 & & & & \\
TSE5 & & & & \\
\hline
\end{tabular}


Appendix 3. Factor Correlation Matrix (4-factor model)

\begin{tabular}{lllll}
\hline & Factor1 & Factor2 & Factor3 & Factor4 \\
\hline Factor 1 & 1.000 & .679 & -.493 & .274 \\
Factor 2 & .679 & 1.000 & -.343 & .161 \\
Factor 3 & -.493 & -.343 & 1.000 & -.089 \\
Factor 4 & .274 & .161 & -.089 & 1.000 \\
\hline
\end{tabular}

Extraction Method: Maximum Likelihood.

Rotation Method: Promax with Kaiser Normalization. 
Appendix 4. Relationships among motivational factors and grade (Stage 5)

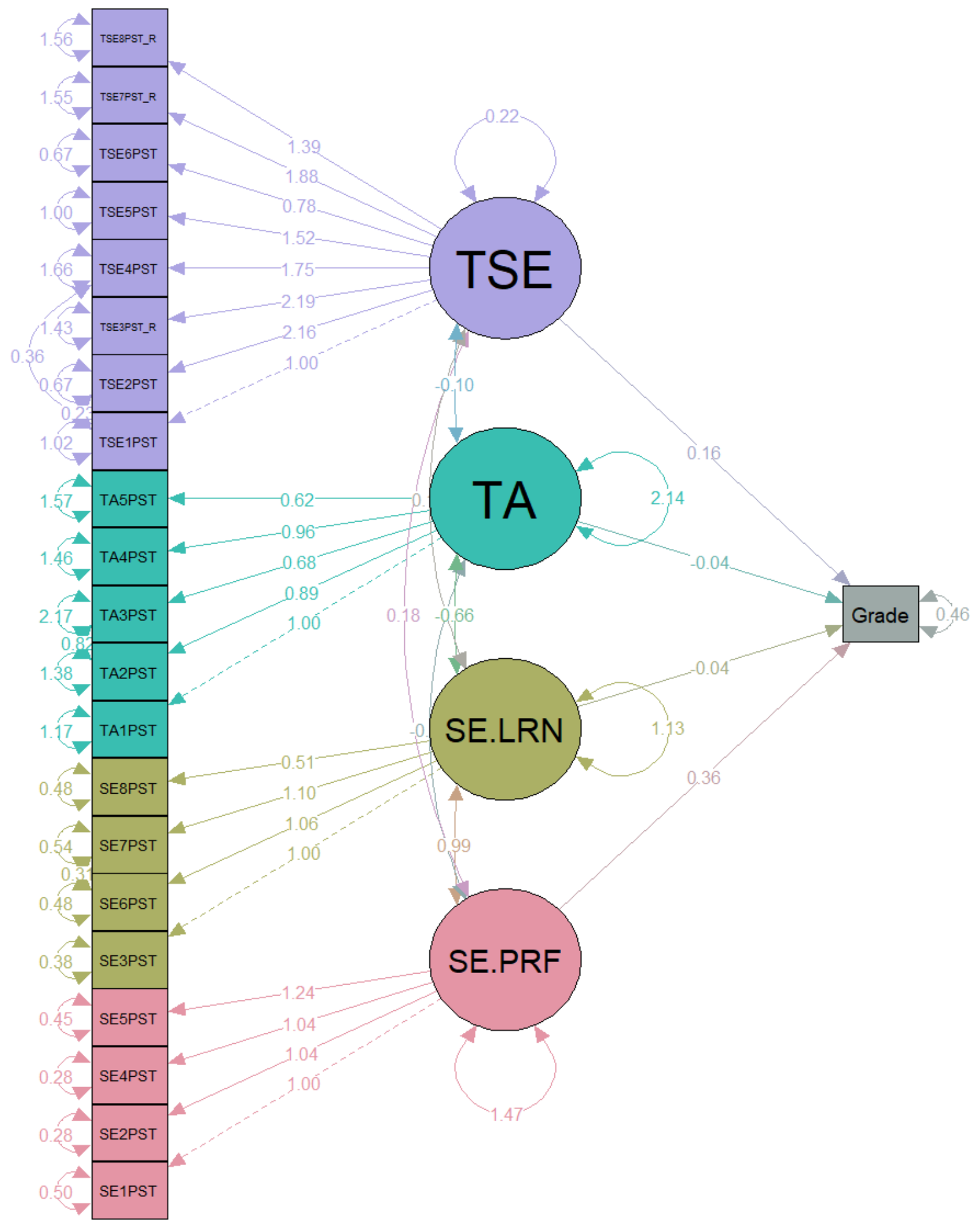

